\title{
Two Sides of a Coin: The Social Networking Sites
}

\author{
Vivek Kumar Garg $1 *$, Neelam Goel ${ }^{2}$, Seema Singh ${ }^{3}$ and Dharambir Kashyap ${ }^{4}$ \\ ${ }^{1}$ Demonstrator, Department of Biochemistry, Government Medical College and Hospital, Chandigarh, India \\ ${ }^{2}$ Assistant Professor, University Institute of Engineering and Technology, Punjab University, Chandigarh, India \\ ${ }^{3}$ Senior Resident, Department of Biochemistry, Government Medical College and Hospital, Patiala, Punjab, India \\ ${ }^{4}$ Research Scholar, Postgraduate Institute of Medical Education and Research, Chandigarh, India
}

*Corresponding author: Vivek Kumar Garg, Demonstrator, Department of Biochemistry, Government Medical College and Hospital, Chandigarh, India, Tel: +91-9316977277; Email: garg.vivek85@gmail.com

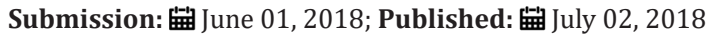

\section{Short Communication}

Social networking sites are web based services which help the individuals to create their profile by filling their personal details and to connect with the world and their friends, family members in foreign. People get the information related to entertainment, science, researches, medical education etc. But these sites also have negative effect on the health of users and on the relationships [1]. Mostly youngsters are on these networking sites like Facebook, Twitter, Hike, Snapchat, Instagram and are connected to the friends around the world but not with their family members which are present in their homes [2]. They are going away from the relationships. Mostly males are on these sites than females but males get knowledge from these sites. The students get less mark as students spend their most of the times on these sites even in the examination time [3].

It also increases the cyber crime and more thefts occur via these networking sites. The health system become deteriorate, eyes weaken, obesity increases and stress level increases due to these social sites. Sometimes, youngster minds become divert to crime and they got involved in many rackets. Just like coin, these sites also have some positive effects on youth, students, and adults also [4]. Individuals become aware to the environment and all types of pollution, adventures, and shopping, cooking, places to see, medical research, and tragedies happening around the world, negative effects of drugs, alcohol, and smoking [5]. Nowadays, people give space to ambulances on roads. People learn all these moral values from the posts shared on these sites. So we cannot ignore the good side of these social networking sites. People should spend their time on these sites to get knowledge, to keep in touch with the world but spending overtime can ill effect on their health and also on the relations around them.

\section{Financial Support and Sponsorship}

Nil.

\section{Conflict of Interest}

None.

\section{References}

1. Khurana N (2015) The Impact of Social Networking Sites on the Youth. J Mass Commun Journal 5(12): 10-13.

2. Kuppuswamy S, Narayan PBS (2010) The Impact of Social Networking Websites on the Education of Youth. Int J Virtual Communities Soc Netw 2(1): 67-69.

3. Khan S (2011) Impact of Social Networking Websites on Students. Abasyn J Soc Sci 5(2): 56-77.

4. Jain, Madhur Raj, Palak Gupta NA (2012) Impact of social networking sites in the changing mindset of youth on social issues - a study of delhincr youth. Int Ref Res J 2(2): 36-43.

5. Garg VK, Kashyap D (2018) Smoking Habit among Youngsters. J Addict Prev 6(1): 1.

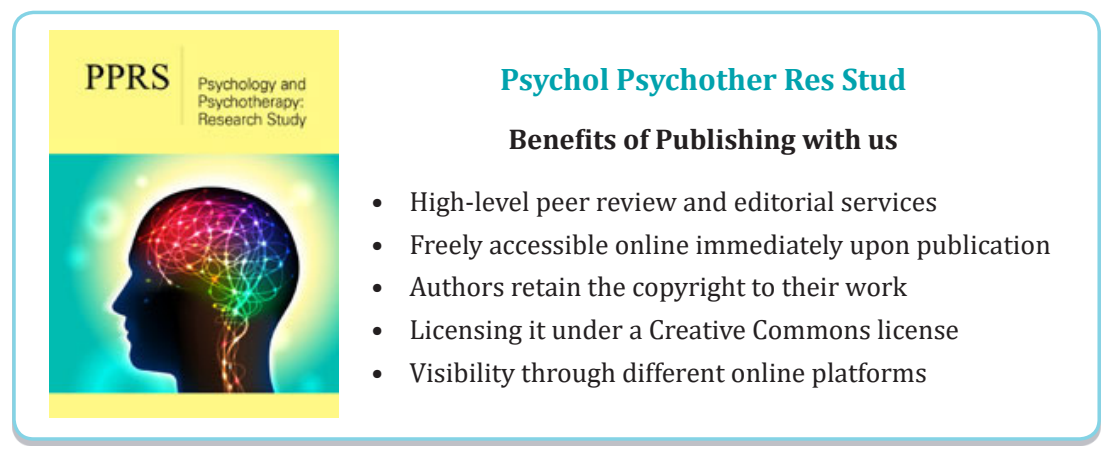

